\title{
MIR1243 Pre-miRNA
}

National Cancer Institute

\section{Source}

National Cancer Institute. MIR1243 Pre-miRNA. NCI Thesaurus. Code C142772.

MIR1243 pre-miRNA is an oligonucleotide (93 bases) that is encoded by the human MIR1243 gene and may play a role in the regulation of gene expression. 